\title{
Actualidad de las piezas de museo: Freud y la ecuación etiológica ampliada
}

\author{
Museum pieces today: \\ Freud and the Extended Etiological Equation
}

Pablo Cabrera Pérez ${ }^{1}$

\section{Resumen}

El texto trata sobre una reconsideración de las claves freudianas para comprender los malestares subjetivos de nuestra época. Incorpora, en las tesis clásicas de Freud sobre las vías de formación de síntoma en relación a lo inconsciente, aquellos descubrimientos posteriores a 1920, relacionados con la herencia y la transmisión, lo originario y lo traumático, lo que hemos llamado ecuación etiológica ampliada. Se argumenta que esta consideración sobre otras claves freudianas permite discutir de manera compleja las nuevas enfermedades del alma, o en otros términos, los malestares de la actualidad.

Palabras clave: psicoanálisis, traumatismo, transmisión, subjetividad.

\section{Abstract}

This paper presents a review of Freud's key ideas to understand subjective discomfort in our time. It incorporates discoveries made by the author after 1920, linking Freud's classical theory of symptom formation process -related to the unconscious-, to heritage and transmission, the original and the traumatic, presenting what we have called an expanded etiological equation. It is argued that these considerations allow a further and more complex discussion about the new soul's diseases, or in other words, today's subjective discomforts.

Key words: psychoanalysis, trauma, transmission, subjectivity.

1 Docente del Departamento de Psicología de la Universidad de Chile. Investigador de la Unidad Traumatismos, memorias y procesos de simbolización e investigador colaborador del núcleo de investigación Lapsos (Iniciativa Bicentenario), Facultad de Ciencias Sociales, Universidad de Chile, Santiago, Chile. E-mail: pcabrerap@u.uchile.cl 


\section{Introducción}

El museo antes que ser un espacio de exhibición de obras de acuerdo al canon y las políticas del campo del arte, trata sobre las condiciones necesarias -espacio temporales- para que la obra se disponga a ejercer su poderío sobre los procesos de subjetivación, o en otra clave, para salvaguardar los vestigios y las ruinas de un tiempo anterior. El lugar de encuentro abre un espacio-otro para que lo que vemos, si seguimos a Didi-Huberman (2004), nos mire, y el buen lector deje que la obra trabaje en él, con él, más allá de su propio saber sobre el objeto y lo que en él mismo, pone en curso (Anzieu, 1993). Nos muestra así uno de los modos en que el sujeto accede al tiempo, a la historia, a las huellas y olvidos desde lo actual. La condición de esa experiencia estética, si podemos llamarle así, trata sobre el entramado que acontece entre la historia de la cultura, la propia historia subjetiva y la experiencia in situ, vale decir, con todo aquello ausente que logra hacerse ver. En ese sentido, la experiencia es un instante presente liminar, que trabaja un tiempo a-temporal (Freud, 2007h), dada la íntima relación que habría entre la percepción y las memorias inconscientes. Este estatuto del tiempo y del ejercicio de historización, parte del supuesto de un sujeto descentrado -entre los sistemas Inconsciente, Preconsciente, Conscienteque de acuerdo al saber psicoanalítico, es fundamental para el ejercicio de su praxis, así como para la apertura de la experiencia estética. La situación actual del museo y del arte mismo (Aumont, 2001) se puede leer como una crisis que atraviesa la condición de la experiencia de la subjetividad respecto de sí (Agamben, 2007; Arendt, 2007). Cabe preguntarse si esa metamorfosis muestra el ocaso de una cultura y de ese descentramiento del sujeto, o más bien, si la vía más simple y precaria para pensar esa crisis y sus modos de expresión trata sobre la negación de lo real que tramita ese descentramiento en sus destinos pulsionales -sea por la vía del síntoma, la angustia o la elaboración- encontrando su salida en el porvenir de una ilusión respecto a lo nuevo, lo inédito.

Esto cobra un sentido específico en la discusión psicopatológica en el campo psicoanalítico. El síntoma es una formación de lo inconsciente. En ello, lo actual repite una escena anterior, reprimida, la que entrará en 
complejas relaciones con la angustia y la inhibición (Freud, 2007p). Es por esta razón, que el síntoma abre una dimensión privilegiada, para discutir la diferencia entre lo nuevo y lo actual. Más aún, si consideramos que en nuestro contexto ya es un lugar común hablar sobre las formas inéditas de ser sujeto, así como la emergencia de las nuevas enfermedades del alma y sus malestares culturales respectivos (Kristeva, 1995).

Y entonces jes cierto que en lo actual encontramos algo nuevo? La hipótesis que propongo desarrollar es la siguiente: reconociendo la dificultad en el trabajo de elaboración y el atravesamiento de la resistencia, el trabajo psicoanalítico oscilará entre el análisis de las formaciones de lo "inconsciente" y del "yo" (Freud, 2007r). En esa oscilación, y en particular en aquellos casos clínicos en donde se presenten dificultades de otro orden en la elaboración y la resistencia, como en las nuevas enfermedades del alma, en cuadros psicosomáticos, o en sujetos que han vivido experiencias extremas, habrá que introducir en el análisis y su escucha las problemáticas propias de lo originario y los efectos del encuentro con el Otro, así como la transmisión de las generaciones anteriores y lo traumático. Estos ejes complejizan el trabajo analítico y las tesis clásicas en torno a las alteraciones del yo, las cuales se producirían como consecuencia de los efectos de la lucha en contra del retorno de lo reprimido y, luego, respecto del síntoma.

Los descubrimientos que sistematizara Freud, desde 1920 en adelante, permiten abrir dimensiones que requieren ser introducidas en el trabajo psicoanalítico para poner en curso los procesos de pensamiento y elaboración, así como para comprender algunos aspectos de los propios malestares actuales de las sociedades contemporáneas (Kristeva, 1995). Sus indicios más reveladores, a nuestro juicio, se refieren a la negación, en la experiencia de sí, de la inquietante extrañeza, así como el desconocimiento del otro en cuanto otro distinto.

\section{Antecedentes}

Notas en torno a las nuevas organizaciones subjetivas

Hace más de medio siglo que en las humanidades y las ciencias sociales se tematiza el ocaso y crisis sin retorno de la subjetividad moderna, 
con ocasión de las transformaciones culturales, las catástrofes sociales y políticas del siglo XX e inicios del XXI, la aceleración creciente de la vida cotidiana, el asentamiento del neoliberalismo y su fuerte inserción económica como derrotero organizador de lo político, lo cultural y lo subjetivo. Una de sus consecuencias se observarían en las dificultades a nivel del trabajo de la representación y, por consiguiente, de elaboración (Benjamin, 1989; Kristeva, 1995; Marcuse, 1970). De acuerdo a ello, el sujeto contemporáneo, posmoderno, habría cambiado la relación que sostiene respecto a sí mismo, al cuerpo, al otro y al campo social (Bauman, 2001; Lipovetsky, 2007; Zizek, 2003).

Estos fenómenos se harían evidentes en el propio trabajo psicoanalítico, encontrando su traducción en una nueva nomenclatura psicopatológica, poniendo en discusión las nociones clásicas de la psicopatología (Rojas, 2008) y las nociones estructurales de neurosis, perversión y psicosis (Dör, 2006). Al respecto Missenard (1991) plantea:

La clínica ha cambiado. Los casos clínicos son sin duda más difíciles que los del pasado. El reclutamiento de neuróticos en la burguesía vienesa, no coincide (...) con el nuestro. Ciertos pacientes contemporáneos se encuentran en una dificultad para pensar, que no es solo del orden de la prohibición o de la inhibición (...) neurosis de vacío, patologías narcisistas, enfermedades del ideal (p. 14).

Freud y la introducción de lo heteróclito en el análisis de las formaciones de lo inconsciente

La teoría de la represión (Freud, 2007g) permite leer tanto la formación de una cultura como al sujeto y las formaciones de lo inconsciente (Freud, 2007d). El prototipo de ese malestar, al menos en la época de Freud, se refiere a los caminos de formación de síntoma y el acrecentamiento de la culpa, regulando, de este modo, las tramitaciones pulsionales y las exigencias de la vida en comunidad en la asunción del ideal del yo (Freud, 2007q; Kaës, 2002).

El síntoma en tanto formación de lo inconsciente mantendrá estrechas relaciones con el olvido -o lo reprimido-, con la emergencia de la 
angustia y con el terreno de la inhibición (Freud, 2007p). Por otro lado, la naturaleza misma del síntoma es una composición de materiales heteróclitos, estando el mismo sobredeterminado (Freud, 2007b). Para dar cuenta de esta extraña composición, Freud propuso la llamada ecuación etiológica (Freud, 2007i) ${ }^{2}$.

Los materiales que encontramos en la formación de un sujeto implican a lo histórico (predisposición) y a lo actual. Los primeros, son el factor condicionante de la formación de síntomas. Este factor involucraría lo trasmitido por herencia y lo adquirido en las vivencias de la sexualidad infantil, que serían reprimidos en lo inconsciente. Lo actual, en cambio, se refiere a traumas auxiliares del presente (Freud, 2007i). En un segundo ámbito de la ecuación, lo histórico y lo actual se relaciona con el trabajo de ligazón que lleva a cabo el sujeto, involucrando un tiempo de inscripción y una topo-grafía (Icc-Prcc-Cc), introduciendo, en ese ejercicio de ligazón, los efectos de lo retroactivo (Laplanche, 2001).

Junto a lo anterior, la ecuación etiológica articula una intensidad pulsional que el sujeto deberá tramitar por la vía del pensamiento y su domeñamiento. Esa acción sería análoga a una satisfacción lograda por medio del trabajo psíquico. Si esa intensidad cobrara mayor magnitud, debido a frustraciones de deseo, el sujeto se verá sobrepasado y la defensa fracasará en su cometido, teniendo por consecuencia un retorno de lo reprimido inconsciente. La frustración devendrá traumática, en razón del enlace que habría entre una moción frustrada y otra inconsciente. De esta manera, la vivencia dejará de perturbar al sujeto, y la representación reprimida adquirirá una potencia que se hará sentir desde otro lugar y con otra forma: por medio de la formación de síntoma. Forma, ahora, intraducible para el yo, ya que sus contenidos se presentarán desfigurados e irreconocibles respecto a su origen inconsciente, puesto que ese trabajo de formación se realizará mediante la censura y los procesos primarios. Freud (2007i) indica que:

2 Freud si bien propone la ecuación etiológica en 1895, será en las Conferencias de Introducción al Psicoanálisis de 1916 donde expondrá de manera nítida lo que ella establece: los destinos de pulsión se organizan en caminos de formación de sintoma; y esos caminos, delatan, en el registro del sujeto, aspectos tópicos, dinámicos y económicos. 
La investidura regresiva de estas lleva a sortear la represión y a una descarga -o satisfacción- de la libido en la que deben respetarse las condiciones del compromiso. Por el rodeo a través del inconsciente y de las antiguas fijaciones, la libido ha logrado por fin abrirse paso hasta una satisfacción real, aunque extraordinariamente restringida y apenas reconocible ya. Permítanme agregar dos observaciones acerca de este resultado final. Consideren, en primer lugar, cuán íntimamente aparecen ligados aquí la libido y el inconsciente, por una parte, y el yo, la conciencia y la realidad, por la otra, si bien al comienzo en manera alguna se copertenecen (p. 328).

Análisis

\section{De la ecuación etiológica ampliada}

Quisiera introducir y comentar algunos elementos específicos referidos a lo histórico y a lo actual en relación a la ecuación etiológica, que el propio Freud descubre entre 1910 y 1938. En este legado, posterior a 1910, y sistematizado desde 1920 en adelante, encontraremos un ahondamiento y problematización del registro fantasmático y las formaciones del "ello", así como las alteraciones del "yo" (Freud, 2007r). Se incorporarán de esta manera, respecto a lo histórico, las problemáticas de la transmisión, el narcicismo y el otro, y respecto a lo actual, las vivencias de los traumatismos reales.

\section{Lo histórico en referencia a lo hereditario}

La herencia es parte importante de la discusión psiquiátrica del siglo XIX, específicamente, en el intento de explicar el desarrollo de la psicopatología y sus diferentes modos de presentación (Postel \& Quétel, 2000). Encontramos el modelo de la degeneración, en referencia a un ideal, tal como formula primero Buffon en el siglo XVIII y luego Morel en

3 La ecuación etiológica ampliada hace referencia al término ecuación etiológica utilizada por Freud, agregando de ahí el término ampliada, en la formulación original, los descubrimientos de Freud posteriores a 1920. El término "ecuación etiológica ampliada" fue formulado por primera vez en un texto publicado en el año 2010 (Cabrera, 2010). 
el siglo XIX. En segundo lugar, será importante el modelo epidemiológico y la barrea inmunitaria que sostendrán Pasteur y Koch. Por último, se desarrollará el modelo del contagio mental y de la psicología de las masas con Le Bon (Kaës, 2006).

Freud emplea el término hereditario en distintos campos semánticos. Kaës distingue al menos cuatro usos en su obra. Die übertragung se refiere a lo transmisible en la comunicación por contagio; die vererbung designa lo que se transfiere por legado o herencia; die erwerbung se refiere a la adquisición (proceso) de aquello heredado; y die erblichkeit se refiere a lo heredado por herencia, sea en términos biológicos o legales (Kaës, 2006). Por tanto, cuando Freud indica que la ontogenia re-edita la filogenia de la especie, indica varios sentidos que habrá que especificar. A veces hace referencia a las herencias propias de la constitución. En otras ocasiones, aludirá a las organizaciones singulares que acaecerá en todo sujeto independiente a las transformaciones culturales (dos tiempos de la sexualidad, las fantasías originarias y la represión de la sexualidad edípica). $\mathrm{Y}$ en otras, hará referencia a las herencias subjetivas y culturales de los ancestros que el sujeto tendrá que elaborar, y que Freud indica a través del aforismo de Goethe: lo que has heredado de tus Padres, adquiérelo, para poseerlo (Freud, 2007m).

Freud (2007a) supone a la herencia en la reflexión sobre la psicopatología. Nos indica que:

en la (...) neurosis la herencia cumple el papel de una condición poderosa en todos los casos... Es cierto que no podría prescindir de la colaboración de las causas específicas, pero la importancia de la disposición hereditaria es demostrada por el hecho de que las mismas causas específicas no producirían ningún efecto patológico manifiesto si actuaran sobre un individuo sano, mientras que en una persona predispuesta su acción hará estallar la neurosis (...) (p. 147).

La herencia, en sintonía con la discusión de la psiquiatría del siglo XIX, aborda las variaciones entre individuos en relación a la fuerza (drang) pulsional. La drang se observa en el apremio que impone la pulsión sexual en su inscripción psíquica y posterior trabajo. 
Otra figura de la herencia, la encontramos en el supuesto que Freud comparte con Heackel, siguiendo la filosofía zoológica de Lamarck (Assoun, 1985). El supuesto que plantea es que lo filogenético de la especie se actualiza en la ontogenia. La ontogenia sería una repetición abreviada de la historia de la especie humana. Bajo este supuesto, Freud descubrirá los dos tiempos de la sexualidad interrumpido por la latencia, vía represión (Freud, 2007c). Así también, en el primer tiempo de la sexualidad, acontecerá la sexualidad infantil (perversa y polimorfa). En este período se re-actualizarán en cada infans los fantasmas originarios (urphantasien): la escena primaria, el fantasma de seducción y de castración, los que luego quedarán sepultados bajo los efectos de la represión.

Hay una tercera dimensión de la herencia que ha sido menos considerada en su obra, que podemos llamar las herencias genealógicas. Freud comienza indagación de ellas en "Tótem y tabú" en donde indaga el origen de la cultura (Freud, 2007d), cuyos supuestos los volverá a revisar a propósito de las masas y el ideal (Freud, 2007l) y el malestar en la cultura (Freud, 2007q), adquiriendo una importancia cada vez mayor en su obra.

En el origen, habría acontecido un acto violento y extremo, con lo cual adviene la cultura. Se desarrolla acá el mito del asesinato real del padre de la horda primitiva, que luego se repetiría metafóricamente en la historia constitutiva de cada individuo (complejo de Edipo). El padre muerto, habría retornado en la forma del ideal. El tótem será nombre y figura. Con él, se inaugura una cultura y sus memorias, así como la construcción de la dimensión ética del individuo, y con ello, la posibilidad del lazo social. El tótem sería una marca de la genealogía cultural en lo actual, con el cual la comunidad encontraría una identificación al ideal, que permitirá su sobrevivencia. Este tendría una función reguladora del lazo social, dado que inscribe una condición a priori de la vida humana, a saber, la condición de la represión del incesto y del asesinato. El a priori se traduce en el pacto social, en donde habría un recurso en la transmisión del nombre y su función. El anverso de esto se puede observar en la culpa generada por la ambivalencia insoslayable que genera el otro cuando se ubica como objeto de un deseo prohibido. 
Lo sorprendente de la tesis freudiana es que se transmitiría esa condición a priori asi como la culpa entre las generaciones, inaugurando lo que podemos llamar las herencias genealógicas en el campo de lo transgeneracional (Kaës, 2006). Dicho en otros términos, se construye un espacio subjetivo de continuidad histórica entre el origen, el fundamento y lo actual. En ese lazo sostenido por un trabajo de cultura y pensamiento, se proyecta el porvenir de ella misma. La disolución de una cultura se provocaría por la transgresión del pacto y, con ello, la falta de reconocimiento del otro. En tal caso, advendrá el campo de la devastación subjetiva, la perversión y el trabajo de desligadura de la pulsión de muerte, o en otra clave, el reinado del sadismo del super yo ejercido en toda su brutalidad en contra del otro, bajo el lema: goza del otro a pesar de todo (Zizek, 2003).

La transmisión se realiza por la vía del ideal, tal como se ha sugerido en otro lugar: el super yo, heredero del complejo de Edipo, se construye a través de la identificación al ideal y super yo de los padres, y el de estos, en filiación a los suyos y a sus ancestros (Cabrera, 2005). Pero por otro lado, hay transmisiones de fragmentos no elaborados por las propias generaciones (Abraham \& Torok, 2005).

Encontraremos así herencias que enlazan al sujeto con la cultura y la historia, trasmitiéndose deudas y traumas que hay que saldar, así como dones generacionales y ancestrales, que el sujeto tendrá que apropiarse por medio del trabajo de elaboración. Cada una de estas trasmisiones impondrán al trabajo psíquico, ejercicios elaborativos de lo desconocido de su tiempo y del tiempo histórico generacional (Freud, 2007j). Nos dice Freud (2007m):

Lo que la biología y los destinos de la especie humana han obrado en el ello y le han dejado como secuela: he ahí lo que el yo toma sobre sí mediante la formación de ideal, y lo que es revivenciado en él individualmente. El ideal del yo tiene, a consecuencia de su historia de formación \{de cultura\}, el más vasto enlace con la adquisición filogenética, esa herencia arcaica, del individuo (p. 38).

Así también, en relación a la insistencia de la transmisión de lo originario que se hace patente en lo actual, Freud (2007s) nos indica: 
Si uno toma a la humanidad como un todo y la pone en lugar del individuo humano aislado, halla que también ella ha desarrollado formaciones delirantes inasequibles a la crítica lógica y que contradicen la realidad efectiva. Si, no obstante, han podido exteriorizar un poder tan extraordinario sobre los hombres, la indagación lleva a la misma conclusión que en el caso del individuo: deben su poder a su peso de verdad histórico-vivencial, que ellas han recogido de la represión de épocas primordiales olvidadas (p. 270).

\section{Lo histórico en referencia a lo infantil: la cosa sexual, el otro y dilemas del} narcicismo originario

Tal como se establece en la ecuación etiológica ampliada, lo histórico convoca a la herencia con sus diversas dimensiones. Una operación análoga encontraremos en la referencia a lo infantil. Freud da cuenta que junto a la herencia están los acontecimientos de la sexualidad infantil, que posteriormente serán reprimidos. En esos acontecimientos, sin embargo, junto a la emergencia del autoerotismo y sus inscripciones representantes de pulsión, se ubicarán los pasajes del narcicismo primario, así como el narcicismo originario. En cada uno de esos movimientos, el Otro ocupará un lugar condicionante de los procesos psíquicos del sujeto en formación.

Lo infantil señala un tiempo y una modalidad de organización subjetiva en formación. Lo que caracteriza al tiempo de lo infantil es el desamparo real y su dependencia al Otro. Sin embargo, no es un recurso suficiente la presencia y cercanía del otro. En el encuentro entre la cría y el otro se ponen en movimiento procesos primarios muy complejos. Estos enlazan la conservación del cuerpo, al mismo tiempo, que ponen en curso las condiciones de la vida psíquica posterior. La madre cuando amamanta, podría -término condicional- llegar a saciar el hambre y el amor del infante. O por el contrario, lo que entrega en el acto de amamantar podría envenenar la precaria vida psíquica, interrumpiendo los procesos de integración y de continuidad del existir, llegando a cobrar un sentido traumático (Bleichmar, 2002; Winnicott, 2008). 
En este encuentro, la pulsión sexual encontrará un lugar en las primeras satisfacciones propias de la autoconservación, bajo el supuesto del apuntalamiento (Freud, 2007e). El infante en su relación con el pecho inscribirá, nos dice Freud, una primera huella de satisfacción sexual. Posteriormente, buscará la repetición de esa experiencia a través de la alucinación (identidad de percepción). Luego, al fracasar en ese intento, dada la diferencia entre la exigencia de la huella y lo que la alucinación satisface, se verá forzado a buscarla en lo real del objeto, a través de la identidad de pensamiento (Freud, 2007b). De ahí en adelante, la pulsión sexual se abrirá paso entre el cuerpo, la fantasía y el otro hasta llegar a su consumación en el Edipo y su posterior sepultación (Freud, 2007c).

Será en ese territorio de despliegue de la cosa sexual y de las imposiciones del principio del placer, que el "yo" y el "narcicismo", desde 1910 en adelante, comenzarán a ser tematizados por Freud.

En la tesis freudiana, el "yo" se construye por la vía de la identificación. El "yo" sería la historia de las pérdidas objetales, que se conservarán haciéndolas parte de sí (Freud, 2007m). En el autoerotismo propio de la infancia, debió ocurrir una acción psíquica (la identificación del rasgo del otro), constituyéndose así el llamado narcicismo primario (Freud, 2007e). El "yo" será consecuencia de una diferenciación del "ello", en su intercambio con el otro. Diferenciación primera, entre el cuerpo y el otro, y luego entre el yo, el otro y la cosa sexual. En el primer caso, se construirá un precario límite o superficie de registro (Anzieu, 1995; Aulagnier, 2007; Green, 1986); en el segundo, un espacio psíquico que puede simbolizar tal como nos lo muestra el trabajo del fort-da (Freud, 2007k) y la introducción del símbolo del "no" en las operaciones psíquicas del infante (Aceituno, 2010; Freud, 2007o).

Freud (2007f) nos indica esa dirección:

Este ser muy pronto se halla en condiciones de establecer un primer distingo y de adquirir una primera orientación. Por una parte registra estímulos de los que puede sustraerse mediante una acción muscular (huida), y a estos los imputa a un mundo exterior; pero por otra parte registra otros estímulos frente a los cuales una acción así resulta inútil, pues conservan su carácter de esfuerzo (Drang) 
constante; estos estímulos son la marca de un mundo interior... La sustancia percipiente del ser vivo, habrá adquirido así, en la eficacia de su actividad muscular, un asidero para separar un "adentro" de un "afuera" (p. 11).

Este primer distingo entre el "adentro" y el "afuera", es anterior al trabajo de la simbolización, propia de la re-presentación y el trabajo sobre la ausencia del otro. Es un precario límite que distingue la superficie de un cuerpo y del otro, así como estímulos y montos pulsionales. Es un distingo, además, respecto al registro y respecto al placer. La cría registra en función de una locación, y percibe sensaciones placenteras o displacenteras donde lo sexual ya tiene lugar, de acuerdo a la teoría del apuntalamiento de Freud. Por tanto, hay algo anterior que está plegado. En efecto, en la satisfacción corporal, propia de la autoconservación, se apuntala la satisfacción autoerótica de la pulsión sexual. Esa huella inaugural del placer sexual, en su reiteración y bajo la garantía posibilitante del otro, construirá y terminará por imponer, en los precarios procesos psíquicos, más bien sensoriales del infante, el principio del placer.

En el tiempo anterior al del narcicismo primario, encontramos el narcicismo originario $(\sin y o)^{4}$, en donde el cuerpo de la cría está invadido por el cuerpo del otro. Según Aulagnier (2007), la “(...) primera representación que la psique se forja de sí misma como actividad representante se realizará a través de la puesta en relación de los efectos originados en su doble encuentro con el cuerpo y con la psique materna” (p. 31). Esa anterioridad al principio del placer, ese más allá del principio del placer, tiene por destino lograr la dis-tensión desligada propia de la nada. Trata de la consumación de la pulsión de muerte, ahora sin retardo ni repetición; en una imagen, será el instante sin tiempo, por excelencia. En este sentido, Freud (2007k) afirma:

Lo que resta es bastante para justificar la hipótesis de la compulsión de repetición, y esta nos aparece como más originaria, más elemental,

4 Aulagnier (2007) ha caracterizado los procesos subjetivos de este tiempo con el término procesos originarios. El término narcicismo originario intenta enfatizar, en ese mismo tiempo, el cuerpo, la sensación y el registro que acontece. Se diferencia del narcisismo primario, constitutivo del yo, en tanto en aquel no hay aún diferenciación tópica, pero hay procesos en juego en donde el cuerpo del infante y los procesos de elaboración, cuidado, conservación y transmisión del otro auxiliar son nodales. Esto también lo podemos encontrar en distintas claves como las trabajadas por Green (1986), Anzieu (1995), entre otros. 
más pulsional que el principio de placer que ella destrona. Ahora bien, si en lo anímico existe una tal compulsión de repetición, nos gustaría saber algo sobre la función que le corresponde, las condiciones bajo las cuales puede aflorar y la relación que guarda con el principio de placer, al que hasta hoy, en verdad, habíamos atribuido el imperio sobre el decurso de los procesos de excitación en la vida anímica (p. 23).

Freud junto a las angustias neuróticas identificará las llamadas angustias originarias anteriores a la formación de síntoma (Freud, 2007p). Ellas varían de individuo en individuo y pueden emerger en distintos momentos y contextos. Serán las angustias originarias las que muestran en el registro del afecto un tiempo anterior al de la representación. Ellas pueden hacerse presentes en la actualidad, pero convocan este tiempo originario. "En la primera infancia (lo que acá llamamos narcicismo originario), la impresión que deja el rostro del bebé ante la desaparición de la madre (pérdida de un rasgo de objeto o de alteración) es de dolor y angustia al mismo tiempo. 'Parece que en él marchara algo que luego se dividirá. Aún no puede diferenciar entre ausencia temporaria y verdadera'"(Cabrera, 2010, p. 40). El infante, en el inicio de su existencia, aún no tiene una relación al tiempo y a la representación que le permita anticipar y proyectar la ausencia-presencia del otro. En el registro del afecto, lo que emerge es un tipo de angustia cercana al terror propia de los traumatismos reales. "La pérdida implica quedar a merced de la pulsión sin aplicación, lo que genera angustia y con ello, angustia automática del orden del terror, en tanto en esta fase originaria no hay seña ni apronte angustiado preparatorio" (Cabrera, 2010, p. 40).

\section{Lo actual en el limite del presente o los traumatismos extremos 5}

En la ecuación etiológica y la formación de síntoma, "lo actual" es secundario (se puede presentar o no) dado que lo fundamental tiene

5 Aspectos muy importantes de este apartado los hemos recogido de la investigación realizada en el Proyecto Semilla: "Traumatismos y procesos de simbolización” (2011-2012), realizada por la Unidad de Investigación "Traumatismos, memorias y simbolización" del Departamento de Psicología de la Universidad de Chile. 
relación con el retorno de lo reprimido. "Lo actual" es gatillante, pero no condición, tal como fue desarrollado anteriormente. En ello radica la importancia que Freud le da al fantasma inconsciente en la realidad psíquica, por sobre la realidad social del presente. Este ha sido un descubrimiento de una agudeza y actualidad que ha significado un aporte sin lugar a dudas para el conocimiento de lo humano, así como para el trabajo psicoanalítico. Las enfermedades de la vida anímica, nos dice Freud, son reales. "Ellas poseen realidad psíquica, por oposición a una realidad material, y poco a poco aprendemos a comprender que en el mundo de las neurosis la realidad psiquica es la decisiva" (Freud, 2007i, p. 336).

En relación al trauma, Freud (2007i) plantea que:

la expresión "traumática" no tiene otro sentido que (...) el económico. La aplicamos a una vivencia que en un leve lapso provoca en la vida anímica un exceso tal en la intensidad del estímulo que su tramitación o finiquitación por las vías habituales y normales fracasa, de donde por fuerza resultan trastornos duraderos para la economía energética (p. 33).

En este contexto, y luego de ser testigo de la devastación europea y subjetiva en el contexto de la gran guerra europea (1914-1918), Freud descubrirá el más allá del principio del placer (Freud, 2007k), problematizando en ocasión de los eventos traumáticos, los efectos de ellos en la vida psíquica. Lo traumático adquiere un valor primario, a diferencia del trauma auxiliar de la ecuación etiológica. Ese más allá del principio del placer convocará una reformulación económica, de los destinos de pulsión, en donde la compulsión a la repetición, en un nivel refiere a las satisfacciones inconscientes (Freud, 2007e), pero en un tiempo más primigenio y en un movimiento de mayor profundidad de la vida anímica, retrata el retorno a lo inorgánico y las desligaduras que llevan a la muerte. Introduce así en la economía psíquica, junto a la pulsión erótica, la llamada pulsión de muerte.

Uno de los fenómenos que lo orientan en el descubrimiento de la pulsión de muerte y que problematiza el valor de los traumatismos extremos, son los sueños de los sujetos traumatizados por la guerra. En 
ellos, con ocasión del evento devastador, se subvierte el propio principio del placer, así como las condiciones de elaboración. Los sueños de la neurosis de guerra, harían regresar al sujeto a la escena traumática con todo el terror desencadenante, y por lo tanto, no cumplirían su condición de satisfacer un deseo sexual de la infancia (Freud, 2007b). En la vuelta a recorrer la escena traumática, en cambio, el sujeto intentaría consumar un requerimiento estructural del aparato psíquico, el que ha sido dañado por el traumatismo extremo. Lo traumático habría desmontado el principio del placer, afectando la condición del pensamiento y de la propia elaboración de la escena traumática. Efectivamente, el regreso a lo traumático a través del recurso del soñar, es un intento precario y fallido de elaboración. Es un regreso, podríamos conjeturar, aporético. Retorna para atravesar la escena del trauma, pero ahora, con el apronte angustiado que en su momento requería para no ser devastado. Dado que en su origen fue traumático, ese retorno se repite. Lo agravante de este tipo de repetición, es que el eterno retorno en cada vuelta expande el daño sobre la superficie subjetiva, al modo del lento trabajo de la gangrena que va subsumiendo las profundidades del órgano desde cada capa y superficie.

A diferencia del trauma auxiliar que se liga a lo reprimido, el acontecimiento traumático tiene por condicionem sine qua non, el factor sorpresa, y por tanto, trata sobre lo limite en lo actual, lo sin-anticipación y sin-tiempo. Lo in-pensable del factor sorpresa, dice Freud, hace emerger angustia en lugar de terror, adquiriendo un valor en sí mismo. Su carácter sorpresivo deja al sujeto en un estado de desamparo sin anticipación posible. Esa es la razón por la cual el acontecimiento arrasaría con la última barrera anti-estímulo, inclusive, su bastión límite, sostenido por el apronte angustiado. Este último, prepara, y con ello, protege al propio sujeto en su alerta anticipatoria. "Llamemos traumáticas a las excitaciones externas que poseen fuerza suficiente para perforar la protección antiestímulo. Creo que el concepto de trauma pide esa referencia a un apartamiento de los estímulos que de ordinario resulta eficaz" (Freud, 2007k, p. 29).

En esta formulación sobre lo in-esperado, hay un aspecto económico, pero hay además un elemento a incorporar que está condensado en el término protección anti-estímulo, que se tiende a omitir en la lectura de 
Freud, dejando fuera la realidad del acontecimiento y su dimensión cualitativa, y no solo cuantitativa.

En los tiempos originarios, la protección anti-estímulo es una $b a$ rrera que construyó y la sostuvo el Otro en relación a la cría, tal como comentamos anteriormente. Ese Otro no se refiere a una presencia, sino y sobre todo, a su función de yo-auxiliar, cuya condición está dada por la represión en la estructuración psíquica, y una relación básica en los procesos de pensamiento en relación a sí mismo. Esta es la condición para que el bebé sea reconocido como otro distinto, y no como una mera prolongación del cuerpo. En otro plano, la barrera protectora en un nivel social, da cuenta de la condición de toda cultura regida por el derecho: la inscripción del pacto social (Freud, 2007d). El anverso del pacto es el reconocimiento de un sujeto como fin en sí mismo. En los Estados de excepción, como pueden ser los regímenes dictatoriales o totalitarios, e inclusive, en ciertos vacíos de los Estados de normalidad, el pacto y el reconocimiento se subvierten causando estragos en la subjetividad y en los lazos comunitarios (Kaës \& Puget, 1991).

En ese sentido, la barrera es una metáfora en lo real. La destrucción de la barrera anti-estímulo y el efecto in-esperado en el campo de lo traumático, no implica solamente una dimensión económica, sino que también, el derrumbe de las llamadas garantías basales para el ejercicio del pensamiento y cultura, en último término, para la existencia del sujeto psíquico. Razonado de este modo, cobran todo su sentido algunos planteamientos en donde lo traumático implica al sujeto traumatizado al mismo tiempo que la perversión del lazo social y la transmisión de lo traumático (Aceituno, 2010; Davoine \& Gaudillière, 2010).

En efecto, lo traumático no solo ha interrumpido un proceso de elaboración, sino que ha dejado un fragmento de realidad vivenciada en una condición agravante: la condición de la imposibilidad de toda elaboración de esa vivencia mientras no se restituya la desgarradura que ha dejado el trauma en el narcicismo originario. Condición, que toma sus condicionantes menos de la vivencia que de aquello que desgarró del propio aparato psíquico. Eso devastado del aparato de elaboración abarca aquellas conquistas subjetivas tejidas en el encuentro entre la cría humana y el 
Otro, en donde se logró construir e inscribir, por decirlo en un término, la experiencia del placer inscrita como principio.

El más allá del principio del placer da cuenta de la tendencia originaria del ser humano, y que luego el sujeto trenzará al principio del placer y al de realidad (Freud, 2007n). Es un trabajo en negativo: desligar para conducir a la vida subjetiva a su máxima quietud sin retardo, ni espera, a su desaparición. En lugar de agotar lo pulsional en el trabajo psíquico y cultural, ligando la pulsión de muerte a la erótica, lo no ligado, inclusive, lo no ligable, se traduce en un malestar sin salida, a veces extremo, a veces difuso, impidiendo al sujeto pensar, construir y proyectar su propia existencia.

Será la restitución de lo desgarrado del aparato la condición de posibilidad del trabajo analítico en estas situaciones extremas ${ }^{6}$. Observemos que hay toda una temática que abordar a propósito del trabajo en transferencia, así como lo que abarcan los términos recordar y re-elaborar, en función de las construcciones en análisis y la posición del propio analista (Aceituno, 2010; Davoine \& Gaudillière, 2011).

\section{Discusión}

De acuerdo a lo establecido anteriormente, bajo la rúbrica ecuación etiológica ampliada, se evidencia que tanto las vías de acceso al "ello" como los descubrimientos realizados por Freud a lo largo de su investigación, nos brindan claves fundamentales para identificar e indagar los fenómenos contemporáneos de nuestra cultura, del sujeto y sus sufrimientos psíquicos. Específicamente, nos permite plantear una clínica psicoanalítica que se desarrolle en una relación compleja con lo histórico y lo actual, presentes en el conflicto y su dinámica inscrita en la dinámica entre el ello, el super yo, el yo y la propia realidad psíquica y social. Esa complejidad, nos permite problematizar lo que la literatura psicoanalítica y las ciencias sociales nombran como lo nuevo de la subjetividad en la cultura. En ese

6 Esta temática fue abordada en la presentación de un caso que realizamos en la mesa "Traumatismos, memorias, filiaciones", del II Coloquio Chileno - Francés de Psicoanálisis "Políticas del Malestar y Prácticas Contemporáneas" (Octubre 2011), organizadas en la Universidad de Chile, por el Magíster en Clínica de Adultos de la Universidad de Chile, el Laboratorio de Afecciones Somáticas e Identitarias (LASI) (París X - Nanterre) y el Centro de Investigaciones Psicoanalíticas (Paris VII - Diderot). 
sentido, reconocemos los fenómenos que nombra, al mismo tiempo que pensamos que es posible problematizarlos desde los supuestos desarrollados anteriormente.

Siguiendo a Green (2001), podemos preguntarnos si no será la escucha de los psicoanalistas la que ha variado en lugar de lo que nombran los propios pacientes. $\mathrm{O}$ en otro sentido, ¿cómo dar cuenta del malestar contemporáneo dando lugar en el análisis del "ello", a las dimensiones relacionadas a la herencia, a lo originario y los traumatismos extremos, tal como rastreamos brevemente en la obra de Freud? A nuestro juicio, introducir esas dimensiones y traducirlas en una clínica psicoanalítica, en la escucha del propio analista, en la dinámica de la transferencia, la contratransferencia y los pliegues que actualiza, así como lo que el propio paciente dispone de sí en la realización de su investigación arqueológica, permitiría poner en diálogo el psicoanálisis freudiano con las nuevas indagaciones del psicoanálisis en la actualidad, dado que estos planteamientos tienen como aspecto común, a pesar de sus marcadas diferencias, las dificultades que presentan los pacientes en el trabajo de elaboración, tal como podemos encontrar en los trabajos de Anzieu, (1995), Green (2006), Kristeva (1995), Marty (1991), Missenard (1991), Pommier, (2011), Tisseron (1997), entre varios otros.

Por otro lado, se desprende de la ecuación etiológica ampliada que para que el sujeto analizante y el analista den lugar a aquello que se deja escuchar a través de la asociación libre y la atención libremente flotante, será necesario introducir en complemento a la teoría de la represión, una teoría de la desmentida que incorpore el análisis de las dimensiones antes referidas en torno a lo histórico y lo actual, así como un trabajo en yuxtaposición al análisis del "ello reprimido", considerando una investigación de otro orden que abarque al "ello dinámico", sus trazas y cortes, en el soporte transferencial. Esto ameritaría volver a pensar los términos elaboración, recuerdo, interpretación y construcciones en análisis (Aceituno, 2006), así como el trabajo mismo que lleva a cabo el analista es su propio trabajo asociativo (Davoine \& Gaudillière, 2011).

El psicoanálisis emerge en medio de la desintegración de un mundo en 1900 (Casullo, 1991) y en la articulación del campo de la 
estética que puso como objeto de indagación al sentimiento y a los pliegues de la experiencia (Rancière, 2005). En ello encontramos, además, el marco cultural que el psicoanálisis requiere para ejercer su praxis. En los tiempos actuales, pareciera ser que vivimos en los límites de una cultura, en donde la desmentida del otro y la negación de la diferencia acontecen de manera cotidiana y en escalas de distintas magnitudes. De ahí, que el malestar cultural ponga en relieve la angustia y el miedo al otro, antes que el sentimiento de culpa, así como aquellas interferencias en las vías elaborativas, efecto de las transgresiones sistemáticas del pacto.

En la negación del pacto la experiencia de elaboración se ve afectada por algo real. Sea de manera total como en el terrorismo de Estado o los Estados totalitarios, sea en una transgresión de manera parcial, como se reitera en el abuso sexual, en la violencia intrafamiliar y social, en la violencia de las burocracias institucionales en contra del deseo de trabajar -verdaderos microcampos de concentración de nuestras sociedades actuales- la elaboración no solo se ve interferida, inclusive negada, sino que se ve afectada en su propia tramitación, sea a nivel de las relaciones con el otro, sea a nivel de lo que se logra escuchar y comprender en el trabajo del propio pensamiento psicoanalítico. En ese sentido la negación del pacto la podemos entender de manera precisa como una forma de desmentida de la castración. Por tanto, trataría de una dimensión fundamental: de aquella diferencia que funda el a priori de toda diferencia posterior, posibilitante del reconocimiento del otro y lo Otro y de la propia experiencia en acto que se ofrece al trabajo del pensar.

He puesto en relieve algunos de los descubrimientos que hiciera Freud hace ya muchos años. Estos descubrimientos los hemos articulado con el concepto ecuación etiológica ampliada. La pretensión de este texto consistió en subrayar las dimensiones de lo hereditario, lo originario y los traumatismos extremos, con el fin de ubicar coordenadas y puntos de referencia en relación a lo que hace límite en el trabajo de elaboración. Así también, esas coordenadas buscaron valorar la discusión del psicoanálisis actual, así como algunas problemáticas contemporáneas en relación al malestar en la cultura. Esto último, tan solo fue aludido, señalado, así como el problema mismo de la elaboración y el lazo transferencial. Por último, 
quisimos trasmitir una intuición que el buen lector tendrá que descifrar a propósito de la actualidad de las piezas de museo (espacios y objetos sobrevivientes), que el legado de este investigador de la realidad psíquica y sus pliegues, tal como atestigua la vida de Freud y su obra abierta, insiste y solicita ser trabajada, aún.

Y entonces, si es cierto que lo más arcaico se hace presente en sus restos actuales, a veces en los límites de su desaparición, mostrándose así para ser reconstruido e interpretado ¿cómo escuchar y traducir ese ruido sordo y ubicarlo en tanto sonido, en las escalas de unas historias y en los espacios de un sujeto?

\section{Referencias}

Abraham, N. \& Torok, M. (2005). La corteza y el núcleo. Buenos Aires: Amorrortu.

Aceituno, R. (2006). Los retornos de Freud. Santiago: Palinodia.

Aceituno, R. (2010). Tener lugar. En R. Aceituno (Compl.), Espacios de Tiempo. Clínica de lo traumático y procesos de simbolización (pp. 6981). Santiago: Catalonia.

Agamben, G. (2007). Infancia e historia. Destrucción de la experiencia y origen de la historia. Buenos Aires: Adriana Hidalgo.

Anzieu, D. (1993). El cuerpo de la obra: ensayos psicoanaliticos sobre el trabajo creador. Madrid: Siglo 21.

Anzieu, D. (1995). El pensar. Del yo-piel al yo-pensante. Madrid: Biblioteca Nueva.

Arendt, H. (2007). Responsabilidad y juicio. Buenos Aires: Paidós.

Assoun, P-L. (1985). Introducción a la epistemología freudiana. México: Siglo 21.

Aulagnier, P. (2007). Violencia de la interpretación. Del pictograma al enunciado. Buenos Aires: Amorrortu.

Aumont, J. (2001). La estética hoy. Madrid: Cátedra.

Bauman, Z. (2001). La modernidad y sus descontentos. Madrid: Akal.

Benjamin, W. (1989). Discursos Interrumpidos. Madrid: Taurus.

Bleichmar, S. (2002). La fundación de lo inconsciente. Destinos de pulsión, destinos de sujeto. Buenos Aires: Amorrortu. 
Cabrera, P. (2005). Freud o las problemáticas del malestar en la cultura. Tesis para obtener el título de Psicólogo, no publicada. Universidad de Chile. Santiago.

Cabrera, P. (2010). Tiempo, angustia y subjetividad. En R. Aceituno (Comp.), Espacios de Tiempo. Clínica de lo traumático y procesos de simbolización (pp. 15-42). Santiago: Catalonia.

Casullo, N. (1991). La remoción de lo moderno. Viena de 1900. Buenos Aires: Nueva Visión.

Davoine, F. \& Gaudillière, J.M. (2010). El acta de nacimiento de los fantasmas. Córdoba, Argentina: Fundación Mannoni.

Davoine, F. \& Gaudillière, J.M. (2011). Historia y trauma. La locura de las guerras. Buenos Aires: Fondo de Cultura Económica.

Didi-Huberman, G. (2004). Lo que vemos, nos mira. Buenos Aires: Manantial.

Dör, J. (2006). Estructuras clínicas y psicoanálisis. Buenos Aires: Amorrortu.

Freud, S. (2007a). La herencia y la etiología de las neurosis. En S. Freud, Obras Completas, Vol. 3 (pp. 143-156). Buenos Aires: Amorrortu.

Freud, S. (2007b). La interpretación de los sueños. En S. Freud, Obras Completas, Vol. 5 (pp. 345-608). Buenos Aires: Amorrortu.

Freud, S. (2007c). Tres ensayos de teoría sexual. En S. Freud, Obras Completas, Vol. 7 (pp. 117-222). Buenos Aires: Amorrortu.

Freud, S. (2007d). Tótem y tabú. En S. Freud, Obras Completas, Vol. 13 (pp. 7-162). Buenos Aires: Amorrortu.

Freud, S. (2007e). Introducción al narcicismo. En S. Freud, Obras Completas, Vol. 14 (pp. 71-98). Buenos Aires: Amorrortu.

Freud, S. (2007f). Pulsión y destinos de pulsión. En S. Freud, Obras Completas, Vol. 14 (pp. 113-134). Buenos Aires: Amorrortu.

Freud, S. (2007g). La represión. En S. Freud, Obras Completas, Vol. 14 (pp. 141-152). Buenos Aires: Amorrortu.

Freud, S. (2007h). Lo Inconsciente. En S. Freud, Obras Completas, Vol. 14 (pp. 161-214). Buenos Aires: Amorrortu.

Freud, S. (2007i). Conferencias de Introducción al Psicoanálisis. Parte III. En S. Freud, Obras Completas, Vol. 16 (pp. 221-422). Buenos Aires: Amorrortu.

Freud, S. (2007j). Duelo y melancolía. En S. Freud, Obras Completas, Vol. 14 (pp. 241-256). Buenos Aires: Amorrortu.

Freud, S. (2007k). Más allá del principio del placer. En S. Freud, Obras Completas, Vol. 18 (pp. 7-62). Buenos Aires: Amorrortu. 
Freud, S. (20071). Psicología de las masas y análisis del yo. En S. Freud, Obras Completas, Vol. 18 (pp. 67-136). Buenos Aires: Amorrortu.

Freud, S. (2007m). El yo y el ello. En S. Freud, Obras Completas, Vol. 19 (pp. 13-66). Buenos Aires: Amorrortu.

Freud, S. (2007n). El problema económico del masoquismo. En S. Freud, Obras Completas, Vol. 19 (pp. 165-176). Buenos Aires: Amorrortu.

Freud, S. (2007o). La negación. En S. Freud, Obras Completas, Vol. 19 (pp. 253-258). Buenos Aires: Amorrortu.

Freud, S. (2007p). Inhibición, síntoma y angustia. En S. Freud, Obras Completas, Vol. 20 (pp. 83-163). Buenos Aires: Amorrortu.

Freud, S. (2007q). El malestar en la cultura. En S. Freud, Obras Completas, Vol. 21 (pp. 65-140). Buenos Aires: Amorrortu.

Freud, S. (2007r). Construcciones en análisis. En S. Freud, Obras Completas, Vol. 23 (pp. 259-270). Buenos Aires: Amorrortu.

Freud, S. (2007s). Análisis terminable - interminable. En S. Freud, Obras Completas, Vol. 23 (pp. 219-254). Buenos Aires: Amorrortu.

Green, A. (1986). Narcicismo de vida, narcicismo de muerte. Buenos Aires: Amorrortu.

Green, A. (2001). La nueva clinica psicoanalitica y la teoría de Freud. Buenos Aires: Amorrortu.

Green, A. (2006). El trabajo de lo negativo. Buenos Aires: Amorrortu.

Kaës, R. (2002). La institución y las instituciones. Buenos Aires: Paidos.

Kaës, R. (2006). Transmisión de la vida psíquica entre las generaciones. Buenos Aires: Amorrortu.

Kaës, R. \& Puget, J. (1991). Violencia de Estado y Psicoanálisis. Buenos Aires: Ed. APDH.

Kristeva, J. (1995). Las nuevas enfermedades del alma. Madrid: Cátedra.

Laplanche, J. (2001). Entre la seducción y la inspiración: el hombre. Buenos Aires: Amorrortu.

Lipovetsky, G. (2007). La era del vacio. Ensayos sobre el individualismo contemporáneo. Barcelona: Anagrama.

Marty, P. (1991). La psicosomática del adulto. Buenos Aires: Amorrortu.

Marcuse, H. (1970). El Hombre Unidimensional. Ensayo sobre la ideologia de la sociedad industrial avanzada. Barcelona: Seix Barral.

Missenard, A. (1991). Lo negativo. Figuras y modalidades. Buenos Aires: Amorrortu.

Pommier, F. (2011). Lo extremo en psicoanálisis. Santiago de Chile: Ediciones del Departamento de Psicología, Universidad de Chile. 
Postel, J \& Quétel, C. (2000). Nueva historia de la psiquiatría. México: Fondo de Cultura Económica.

Rancière, J. (2005). El inconsciente estético. Buenos Aires: Fondo de Cultura Económica.

Rojas, H. (2008) Las Concepciones psicopatológicas de Sigmund Freud. Santiago: LOM.

Tisseron, S. (1997). El psiquismo ante la prueba de las generaciones. Clínica del fantasma. Buenos Aires: Amorrortu.

Winnicott, D. (2008). Realidad y juego. Barcelona: Gedisa.

Zizek, S. (2003). Metástasis del goce. Buenos Aires: Paidós.

Fecha de recepción: 15 de marzo de 2012.

Fecha de aceptación: 29 de mayo de 2012. 